\title{
Flavopiridol Mitigates the Progression of Monocrotaline-Induced Pulmonary Hypertension in Rats by Targeting Cyclin-Dependent Kinase 9
}

\author{
Qi Jia ${ }^{1} \cdot$ Zhiqiang $\mathrm{Hu}^{1} \cdot$ Nannan Song ${ }^{1} \cdot$ Weike $\mathrm{Mao}^{1}$ (1)
}

Accepted: 28 October 2021

(c) The Author(s) 2021

\begin{abstract}
Purpose To investigate the role of cyclin-dependent kinase 9 (CDK9) and the therapeutic potential of a CDK9 inhibitor (flavopiridol) in monocrotaline (MCT)-induced pulmonary hypertension (PH).

Methods For the in vivo experiments, rats with PH were established by a single intraperitoneal injection of MCT $(60 \mathrm{mg} / \mathrm{kg})$. After 2 weeks of MCT injection, rats were then treated with flavopiridol $(5 \mathrm{mg} / \mathrm{kg}$, i.p., twice a week) or vehicle for 2 weeks. For the in vitro experiments, human pulmonary artery smooth muscle cells (HPASMCs) were treated with flavopiridol $(0.025-1 \mu \mathrm{M})$ or vehicle under hypoxic conditions. Hemodynamic recording, right ventricle histology, lung histology, and pulmonary arterial tissue isolation were performed. The expression levels of CDK9, RNA polymerase II, c-Myc, Mcl-1, and survivin were determined by qRT-PCR and western blotting, and the proliferation and apoptosis of rat pulmonary arterial tissues and/or HPASMCs were also assayed.

Results Compared to the control group, CDK9 was upregulated in pulmonary arterial tissues from MCT-induced PH rats and hypoxic cultured HPASMCs. Upregulation of CDK9 was associated with enhanced phosphorylation of the C-terminal domain (CTD) of RNA polymerase II (RNA pol II) at serine-2 (Ser-2), promoting the expression of prosurvival and antiapoptotic proteins (c-Myc, Mcl-1, and survivin). Furthermore, treatment with flavopiridol ( $5 \mathrm{mg} / \mathrm{kg}$ ) significantly alleviated pulmonary artery remodeling and partially reversed the progression of MCT-induced PH. Consistently, flavopiridol $(0.5 \mu \mathrm{M})$ treatment decreased the proliferation and induced the apoptosis of cultured HPASMCs under hypoxic conditions. As a result of CDK9 inhibition and subsequent inhibition of RNA pol II CTD phosphorylation at Ser-2, flavopiridol decreased c-Myc, Mcl-1, and survivin expression in isolated pulmonary small arteries, leading to cell growth inhibition and apoptosis.

Conclusion Flavopiridol mitigates the progression of MCT-induced PH in rats by targeting CDK9.
\end{abstract}

Keywords Pulmonary hypertension · Cyclin-dependent kinase $9($ CDK9) $\cdot$ Flavopiridol $\cdot$ Proliferation · Apoptosis

\section{Introduction}

Pulmonary hypertension $(\mathrm{PH})$ is a devastating cardiopulmonary disorder with poor prognosis and limited curative options. Despite receiving treatments, approximately $10-15 \%$ of patients with PH die within 1 year of medical follow-up [1-3]. The remodeling of small pulmonary arteries is an important pathological characteristic of $\mathrm{PH}[3,4]$.

Weike Mao

1984XH0556@hust.edu.cn

1 Department of Anesthesiology, Union Hospital, Tongji Medical College, Huazhong University of Science and Technology, Wuhan, China
Recently, a novel cancer-like concept for PH has emerged because some similarities between cancer and $\mathrm{PH}$ have been confirmed [5-7]. Similar to the hallmarks of cancer cells, pulmonary artery smooth muscle cells (PASMCs) are characterized by overproliferation and resistance to apoptosis $[8,9]$. However, the underlying mechanisms of pulmonary vascular remodeling are not fully understood.

Cyclin-dependent kinases (CDKs) can be divided into partially overlapping classes of cell cycle regulators (e.g., CDK1, 2, 4, 6, and 7) and transcriptional regulators (e.g., CDK7, 8, 9, and 10-13) [10]. CDK9 is a key catalytic subunit of positive transcription elongation factor $b(\mathrm{P}-\mathrm{TEFb})$ that promotes transcription elongation by phosphorylating the C-terminal domain (CTD) of RNA polymerase II (RNA pol II) at Ser-2 [11]. Activation of CDK9 enhances 
the expression of several signal-responsive proteins that regulate proliferation and apoptosis, such as a prosurvival protein (c-Myc) and antiapoptotic proteins (Mcl-1 and survivin) $[12,13]$. The dysregulation of CDK9 activity or expression has been shown to be associated with several diseases, including cancer, cardiac hypertrophy, and acquired immunodeficiency syndrome (AIDS) [11, 14, 15]. Compared to normal tissues, CDK9 overexpression and/or hyperactivity has been observed in several types of cancers (e.g., melanoma) [14, 16-18]. The upregulation of several prosurvival and antiapoptotic proteins (e.g., c-Myc, Mcl-1, and survivin) in cancer cells has been confirmed to contribute to their overproliferation and resistance to apoptosis $[19,20]$. Intriguingly, enhanced c-Myc, Mcl-1, and survivin expression has also been observed in both PH patients and pulmonary artery smooth muscle cells (PASMCs) in PH models [21, 22]. However, whether the enhanced proliferation and resistance to apoptosis of PASMCs in PH is due to the CDK9-mediated overexpression of these targeted genes remains unknown.

Additionally, the inhibition of CDK9 by selective blockers or shRNAs leads to a block in transcription elongation and the suppression of short-living antiapoptotic proteins (e.g., Mcl-1), resulting in an increased rate of apoptosis and antitumor effects $[13,18,20]$. Flavopiridol is one of the most studied CDK9 inhibitors and has been tested in antitumor and cardiac hypertrophy clinical trials [23-25]. Flavopiridol displays potent inhibition against $\mathrm{CDK}$, and its mechanism of action involves the inhibition of CDK9-mediated transcription elongation [24]. Flavopiridol is known to bind tightly to the ATP binding site of CDK9 in a noncompetitive manner to inhibit the CDK9-mediated phosphorylation and activation of RNA pol II, thereby affecting RNA pol II-dependent transcription. Mcl-1, Bcl-2, and Bcl-xL have been shown to be inhibited by flavopiridol treatment, and it is possible that these events are mediated through CDK9 inhibition [26, 27].

Several proteins, including hexamethylene-bisacetamide-induced protein 1/2 (HEXIM1/2), La-related protein 7 (LARP7), and methylphosphate capping enzyme (MePCE) have been shown to negatively regulate the kinase activities of CDK9 or P-TEFb and have also been reported to be involved in CDK9-related diseases [28, 29]. For example, LARP7 downregulation has been confirmed in several cancers, which subsequently potentiates CDK9-mediated transcription elongation and promotes cancer growth and metastasis [30]. However, it remains unknown whether these regulatory proteins are involved in the pathological process of $\mathrm{PH}$.

In the present study, we investigated the roles and underlying mechanism of CDK9 in the cancer-like phenotype (overproliferation and resistance to apoptosis) of PASMCs in PH rats and we sought to elucidate whether a CDK9 inhibitor (flavopiridol) influences the pathogenic progress of $\mathrm{PH}$ by targeting CDK9.

\section{Materials and Methods}

\section{Experimental animals and pulmonary artery hypertension models}

Adult young male Sprague Dawley rats (200-250 g, 2-3 months old) were purchased from the Experimental Animal Center of Weitonglihua Co., Ltd. (Beijing, China). Monocrotaline (MCT) was purchased from Sigma-Aldrich (St. Louis, MO, USA), and it was dissolved in $1.0 \mathrm{~N} \mathrm{HCl}$ at a concentration of $40 \mathrm{mg} / \mathrm{ml}$, adjusted to $\mathrm{pH} 7.4$ with $1.0 \mathrm{~N} \mathrm{NaOH}$ and diluted with distilled water. Flavopiridol was purchased from Selleckchem (Burlington, ON, Canada) and dissolved in dimethyl sulfoxide (DMSO, Sigma-Aldrich). The rats were intraperitoneally injected with MCT $(60 \mathrm{mg} / \mathrm{kg}$ ) or vehicle (normal saline), and once PH was established (2 weeks after MCT injection), the rats with $\mathrm{PH}$ were randomly divided into two groups and treated with either flavopiridol $(5 \mathrm{mg} / \mathrm{kg}$, i.p., twice a week) or vehicle $(0.01 \%$ DMSO) for 2 weeks. All experiments involving animals were performed with the approval of the Animals Care and Use Committee of Huazhong University of Science and Technology (Wuhan, Hubei, China). Up to three rats were housed per cage, and the animals were provided free access to water and food with constant room temperature and humidity maintenance under a $12-12 \mathrm{~h}$ light-dark cycle.

\section{Assessment of right ventricle function and hypertrophy}

The right ventricle systolic pressure (RVSP) of rats was recorded as previously reported [31]. Briefly, at the end of the experiment (4 weeks after MCT injection), the rats from each group were anesthetized (pentobarbital, $50 \mathrm{mg} / \mathrm{kg}$, i.p.) and intubated. The diaphragm was then surgically exposed through the abdomen, and a 25 -gauge needle connected to a pressure transducer (AD Instrument, Sydney, NSW, Australia) was inserted into the right ventricle (RV) through the diaphragm. The RVSP was continuously recorded for $10-15$ min using a PowerLab data acquisition system (AD Instruments). Following hemodynamic recording, the heart and lungs were removed en bloc. The right ventricle (RV) and left ventricle plus interventricular septum $(\mathrm{LV}+\mathrm{S})$ were then separated and weighed to calculate the RV hypertrophy index $(\mathrm{RV} /[\mathrm{LV}+\mathrm{S}])$. 


\section{Histology and morphometric analysis}

The collected lungs were perfused with normal saline and fixed in $4 \%$ paraformaldehyde overnight. The representative cross-sections of the lungs that included the peripheral and the central pulmonary arteries were then sampled and embedded in paraffin blocks. Serial Sects. ( $5 \mu \mathrm{m}$ thick) were then prepared and stained with hematoxylin and eosin to assess vascular pathology. The percent wall thickness (WT $\%)$ of arteries $(15-150 \mu \mathrm{m})$ was calculated using the following formula as previously described: WT $\%=2 \times \mathrm{WT} /$ external diameter $(E D) \times 100$. The percent wall area of arteries was also measured.

\section{Preparation of pulmonary arterial tissue}

The $\mathrm{PH}$ and control rats were anesthetized with pentobarbital sodium $(200 \mathrm{mg} / \mathrm{kg}$, i.p.), and the hearts and lungs were removed after a midline thoracotomy. Intrapulmonary arteries from the lung lobes were aseptically excised and placed in PBS solution. The adherent fat and connective tissues were then carefully removed under a dissecting microscope. The adventitia was scraped using forceps, and the endothelium was carefully removed. The pulmonary arterial tissues were immediately flash-frozen in liquid nitrogen and stored at $-80{ }^{\circ} \mathrm{C}$ for use in the subsequent experiments. Notably, pulmonary arterial tissues from the control group ( 0 week) and MCT groups (1, 2, 3, and 4 weeks after MCT injection) were used to evaluate the effects of MCT on CDK9 mRNA and protein expression.

\section{Cell culture and in vitro experiments}

Human pulmonary artery smooth muscle cells (HPASMCs, passages 4-6, Lonza, USA) were cultured in DMEM at $37^{\circ} \mathrm{C}$ under humidified $5 \% \mathrm{CO}_{2}$. For in vitro hypoxic experiments, HPASMCs were cultured in an incubator equilibrated with $3 \% \mathrm{O}_{2}$ (in $\mathrm{N}_{2}$ ), while control cells were cultured in an incubator equilibrated with room air $\left(21 \% \mathrm{O}_{2}\right)$. Flavopiridol $(0.025-1 \mu \mathrm{M}$ in vehicle) or an equal volume of vehicle (0.01\% DMSO) was added to DMEM during the final $24 \mathrm{~h}$ of exposure to normoxic or hypoxic conditions.

\section{Protein preparation and Western blotting}

HPASMCs were lysed in RIPA buffer (Thermo Scientific, Rockford, IL) supplemented with a protease inhibitor cocktail (Roche, Mannheim, Germany). Cell lysates were centrifuged at $12,000 \mathrm{rpm}$ for $15 \mathrm{~min}$ at $4{ }^{\circ} \mathrm{C}$, and the supernatants were then used as protein samples. Equal amounts of protein $(30 \mu \mathrm{g})$ from each cell type were separated on SDS-polyacrylamide gels and transferred to nitrocellulose membranes (Bio-Rad, Munich, Germany). After blocking with 5\% skim milk in Tris-buffered saline supplemented with $0.1 \%$ Tween 20 for $1 \mathrm{~h}$ at room temperature, the membranes were incubated at $4{ }^{\circ} \mathrm{C}$ overnight with the following antibodies: antiCDK9 (CST, 1:500), anti-RNA pol II (Abcam, 1:1000), anti-phospho-RNA pol II (Ser-2) (Abcam, 1:1000), antiMcl-1 (Abcam, 1:1000), anti-c-Myc (Abcam, 1:1000), antisurvivin (CST, 1:500), and anti- $\beta$-actin (Abcam, 1:3000). The protein levels were normalized to $\beta$-actin. The gel bands were visualized with Amersham ECL prime Western blotting detection reagent (GE Healthcare, Little Chalfont, UK), and the band density was quantified with ImageJ software (National Institutes of Health, Bethesda, MD).

\section{Real-time PCR}

Total RNA from rat pulmonary arteries and HPASMCs was isolated using TRIzol and reverse transcribed with gene-specific primers. Small pulmonary arteries $(<1000 \mu \mathrm{m})$ from $\mathrm{PH}$ or control rats were used for RNA extraction. Real-time PCR was performed as previously described [3]. Specific primers are listed in Table 1.

\section{Cell counting kit-8 (CCK8)}

HPASMCs were seeded in a 96-well plate at a final density of $3 \times 10^{3}$ cells/well [9] and incubated in growth media supplemented with flavopiridol $(0.025-1 \mu \mathrm{M})$ for $24 \mathrm{~h}$.

Table 1 Primer sequences of genes

\begin{tabular}{ll}
\hline Genes & Primer sequences(5'-3') \\
\hline Human-CDK9 & $\begin{array}{l}\text { Sense:ATGGCAAAGCAGTACGACTCG } \\
\text { Antisense:GCAAGGCTGTAATGGGGAAC }\end{array}$ \\
Human-GAPDH & Sense:5'-GAAGGTGAAGGTCGGAGT-3' \\
& Antisense:5'-GAAGATGGTGATGGGATTTC-3' \\
Rat-CDK9 & Sense:5'-CCTCCGGCACTCGTTGGCTG-3' \\
& Antisense:5'-GATTTCGGCTCTGGTTGGT-3' \\
Rat-c-Myc & Sense:5'-CAACGTCTTGGAACGTCAGA-3' \\
& Antisense:5'-TCATCTGCTTGAACGGACAG-3' \\
Rat-Mcl-1 & Sense:5'-TCATCTCCCGCTACCTGC-3' \\
& Antisense:5'-ACTCCACAAACCCATCCC-3' \\
Rat-survivin & Sense:5'-ACCACCGGATCTACACCTTCAAGA \\
& -3' \\
& Antisense:5'-ATTCTCGGTAGGGCAGTGGAT \\
& GAA-3' \\
Rat-Larp7 & Sense:5'-ACGGTATATGTGGAGTTGC-3' \\
& Antisense:5'-AACAACATTGCCACATTTCC-3' \\
Rat-HEXIM1 & Sense:5'-CAGAATTGAGCTGCTTGGA-3' \\
& Antisense:5'-CCAGTGGATAAGTCCTCCC-3' \\
Rat-HEXIM2 & Sense:5'-AGACGAAGACTTCTGGTGG-3' \\
& Antisense:5'-AATCTCCCTTCCTGGTTGC-3' \\
Rat-MePCE & Sense:5'-TCGTCACGGGTAACTATGTC-3' \\
& Antisense:5'-CGGAACATTCTCTTCAGCC-3' \\
Rat-GAPDH & Sense:5'-GCCCATCACCATCTTCCAGGAG-3' \\
& Antisense:5'-GAAGGGGCGGAGATGATGAC-3' \\
\hline
\end{tabular}


Subsequently, the medium was replaced with fresh medium containing $10 \mu \mathrm{l}$ of 2-(2-methoxy-4-nitrophenyl)-3-(4-nitropheny)-5-(2, 4-disulfophenyl)-2H-tetrazole monosodium salt (CCK8, Dojindo, Japan) solution per $100 \mu \mathrm{l}$ of medium. After $2 \mathrm{~h}$ of incubation at $37{ }^{\circ} \mathrm{C}$, the plates were read at $450 \mathrm{~nm}$ using a microplate reader (Thermo, USA). Ten wells were used for each treatment.

\section{5-Ethynyl-2'-deoxyuridine (EDU)}

EDU (RIBOBIO, China) is a thymidine analog that is incorporated into replicating DNA in place of thymine during cell proliferation. The specific activity of the cellular DNA in response to the Apollo fluorescent probe dye is an indicator of cell proliferation. Cells were seeded in a 96-well plate at a density of $3 \times 10^{3}$ cells/well [9], and each group was assayed in triplicate. After $12 \mathrm{~h}$ of synchronization, the cells in each group were treated for $24 \mathrm{~h}$ according to the experimental design, and the medium was replaced with medium containing $25 \mu \mathrm{M}$ EDU as well as the stimulating factor and inhibitor. Subsequently, after incubation for $18 \mathrm{~h}$, the cells were stained, imaged, and counted as the mean of five randomly selected fields under $400 \times$ magnification.

\section{Statistical analysis}

All experiments were performed in triplicate independent experiments. The results are presented as the mean \pm S.E.M., and SPSS version 16.0 (IBM, New York, NY, USA) was used for all the statistical analyses, except where noted. Student's $t$-test and one-way ANOVA with Tukey-Kramer multiple comparisons were used to assess the significance of differences between two or among multiple groups, respectively. Statistical significance was defined at $P<0.05$ for all tests.

\section{Results}

\section{CDK9 is Overexpressed in PH}

First, to investigate whether CDK9 is involved in the development of $\mathrm{PH}$, we measured CDK9 expression in pulmonary arterial tissues from rats with MCT-induced $\mathrm{PH}$. As shown in Fig. 1A, CDK9 mRNA expression was significantly increased at 2, 3, and 4 weeks after MCT exposure ( 2.7, 3.2, and 2.4fold, respectively) compared to that of the control group. Consistent with the upregulation of CDK9 mRNA expression,
A

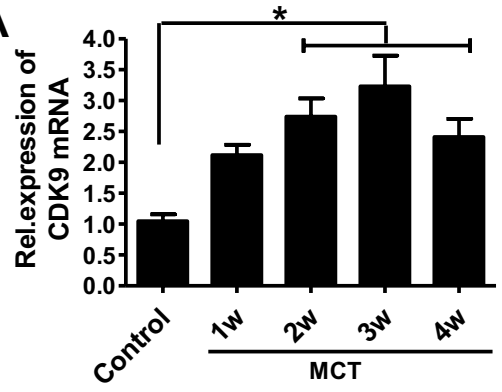

B

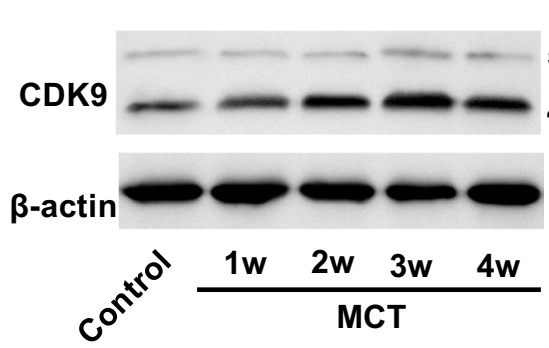

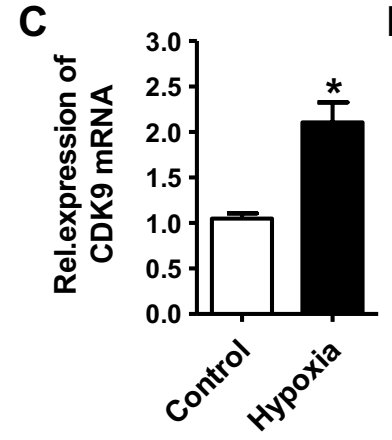

D

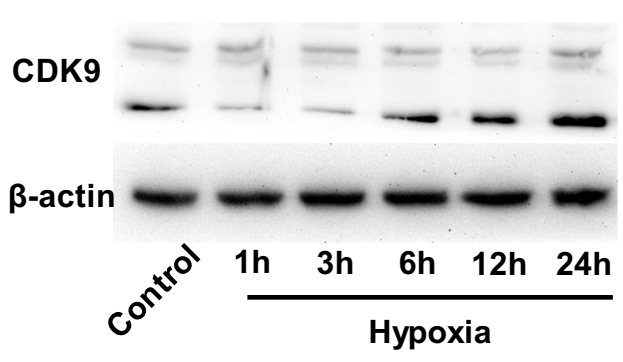

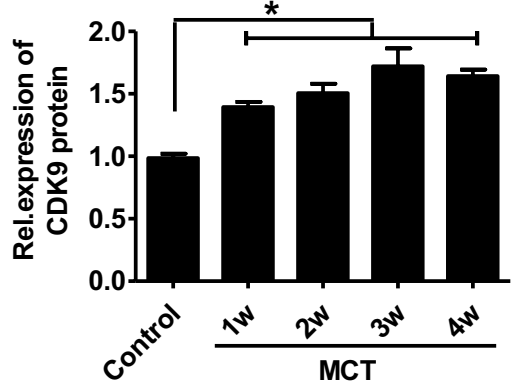

$55 \mathrm{kDa}$ $42 \mathrm{kDa}$ $55 \mathrm{kDa}$ $42 \mathrm{kDa}$

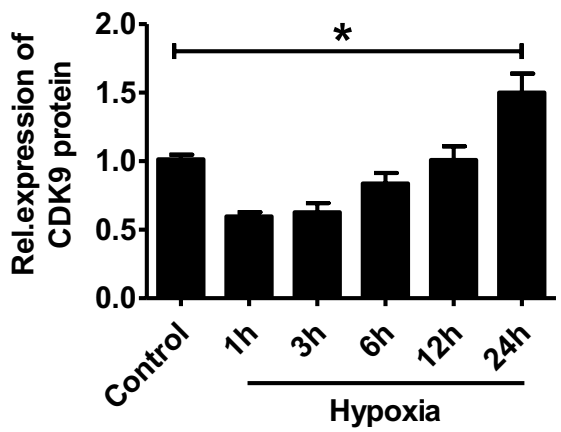

Fig.1 CDK9 is upregulated in pulmonary hypertension in vivo and in vitro. (A) Relative CDK9 mRNA expression in pulmonary arterial tissues of rats during development of MCT-induced PH (1- 4 weeks). (B) Respective images and the summarized data of CDK9 protein expression in pulmonary arterial tissues of rats during development of MCT-induced PH. (C) CDK9 mRNA expression in HPASMCs under control and hypoxia conditions. (D) Respective images and the summarized data of CDK9 protein expression in HPASMCs under hypoxia for 1-24 h. MCT, monocrotaline. Statistical analysis was performed with one-way ANOVA followed by Tukey-Kramer Multiple Comparison or an unpaired the student's $t$-test, $* P<0.05, * * P<0.01$. All values are expressed as the mean \pm SEM, $n=5$ in each group 
CDK9 protein expression was also significantly upregulated at $1,2,3$, and 4 weeks after MCT exposure $(\sim 1.4,1.5,1.7$, and 1.5-fold, respectively) compared to the control group. Similarly, in an in vitro experiment, CDK9 mRNA expression was also markedly increased in HPASMCs exposed to hypoxia for $24 \mathrm{~h}$ hypoxia exposure ( 2.1-fold, Fig. 1C), compared to the normoxic HPASMCs. Interestingly, CDK9 protein expression in the hypoxia group rapidly decreased upon the hypoxia treatment (1-3 h), but it was followed by a gradual increase over time and was $\sim 1.5$-fold greater than that observed in the control group at $24 \mathrm{~h}$ (Fig. 1D).

\section{Flavopiridol Mitigates the Progression of MCT-induced PH in Rats}

To further investigate the functional role of CDK9 in $\mathrm{PH}$, we assessed whether CDK9 inhibition by flavopiridol treatment mitigates the progression of MCT-induced $\mathrm{PH}$ in rats. As expected, the baseline RVSP in the MCT group $(35.1 \pm 2.3 \mathrm{mmHg})$ was significantly higher than that in the control group $(17.7 \pm 0.7 \mathrm{mmHg})$, and CDK9 inhibitor flavopiridiol $(5 \mathrm{mg} / \mathrm{kg})$ treatment significantly decreased the RVSP $(24.4 \pm 1.3 \mathrm{mmHg}, P<0.05)$ of MCTtreated rats when compared to the untreated MCT rats $(35.1 \pm 2.3 \mathrm{mmHg}$ ) (Fig. 2A, B). Additionally, as shown in Fig. 2C-D, MCT promoted a significant increase in the
RV hypertrophy index $(0.57 \pm 0.01, P<0.05)$ compared to that observed in the control group $(0.27 \pm 0.01)$, while flavopiridol mitigated $\mathrm{PH}$ as the RV hypertrophy index was significantly lower in the flavopiridol treated MCT group $(0.45 \pm 0.01, P<0.05)$ than in the untreated MCT group $(0.57 \pm 0.01)$.

\section{Flavopiridol Attenuates the Vascular Remodeling of MCT-induced PH in Rats}

Because the remodeling of small pulmonary arteries is an important pathological characteristic of $\mathrm{PH}[2,8,9]$, we next assessed whether a reduction in pulmonary vascular remodeling of small pulmonary arteries accounts for improved hemodynamics in flavopiridol-treated rats. As shown in Fig. 3A, B, PH in MCT-treated rats was associated with an increase in the media wall thickness of pulmonary arteries, which was significantly attenuated by flavopiridol treatment. Furthermore, as shown in Fig. 3C, immunofluorescence analysis of lung tissue indicated that compared to the control group, the expression of proliferating cell nuclear antigen (PCNA, marker of cell proliferation) in the pulmonary arteries was significantly increased in the MCT-treated rats and decreased when these rats were administered a CDK9 inhibitor (flavopiridol).

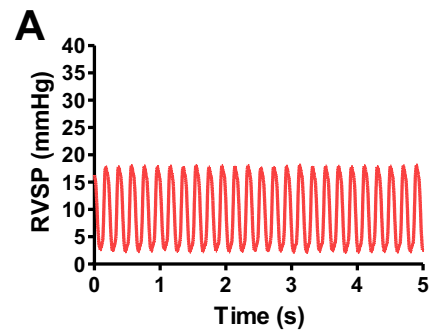

Control

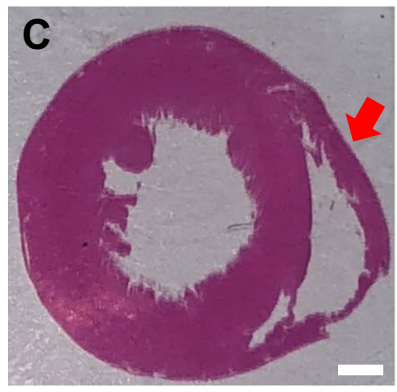

Control

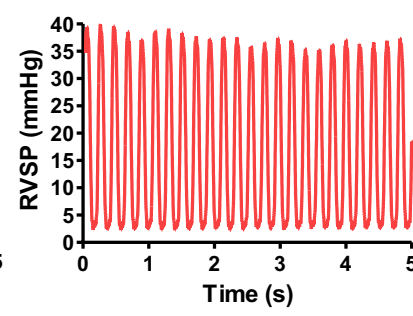

MCT

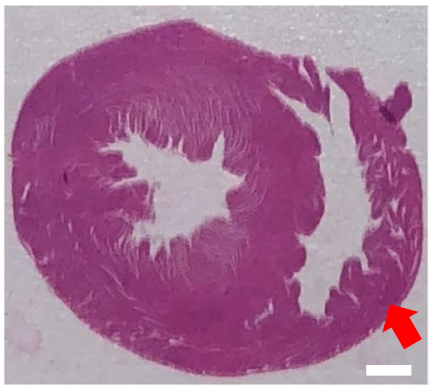

MCT

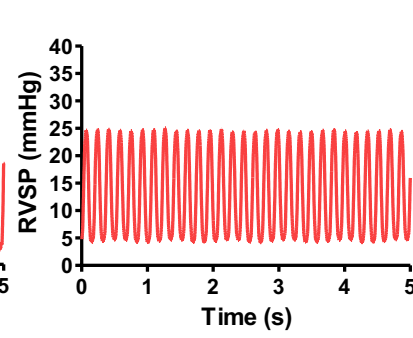

MCT+Fla

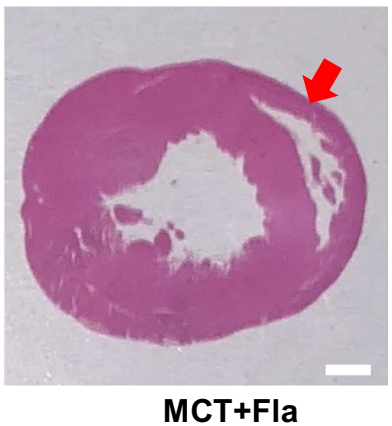

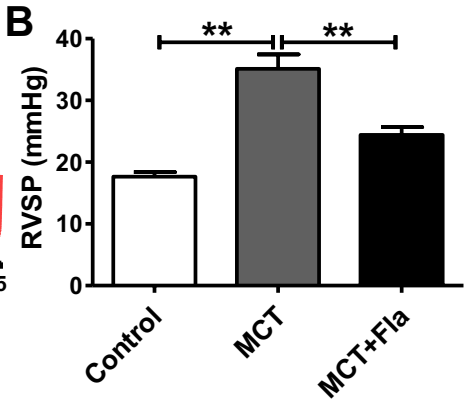

D

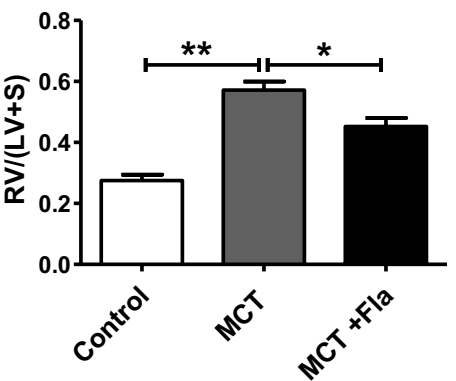

hypertrophy index $(\mathrm{RV} /[\mathrm{LV}+\mathrm{S}])$ in the control, MCT and MCT plus flavopiridol groups. MCT, monocrotaline; Fla, flavopiridol; RV, right ventricle; LV, right ventricle; S, septum. Statistical analysis was performed with one-way ANOVA followed by Tukey-Kramer Multiple Comparison. $* P<0.05$, $* * P<0.01$. All values are expressed as the mean \pm SEM. $n=6$ in each group 
A

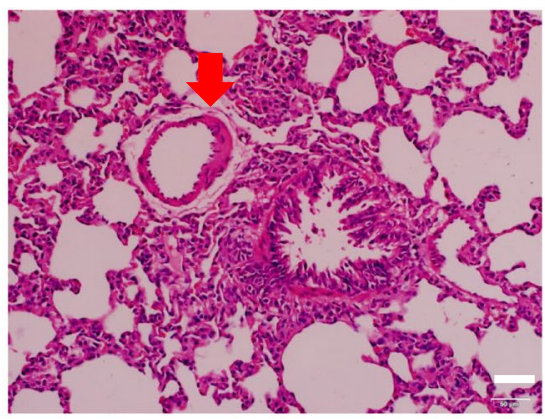

B

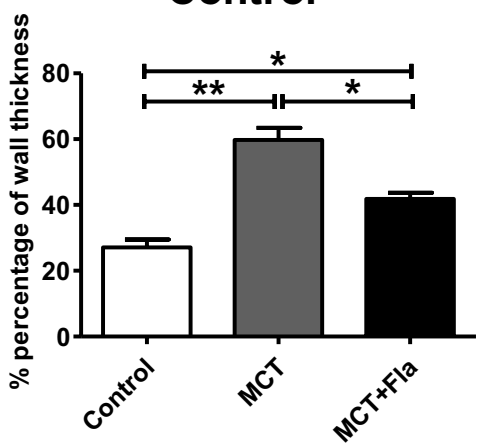

C
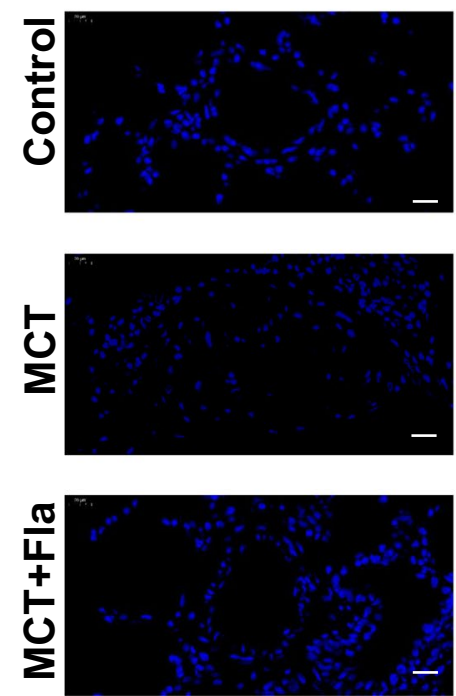

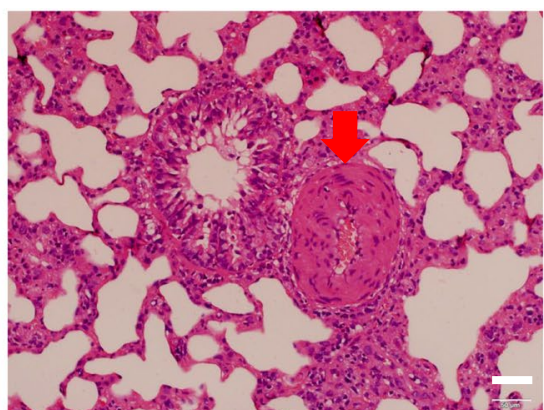

MCT

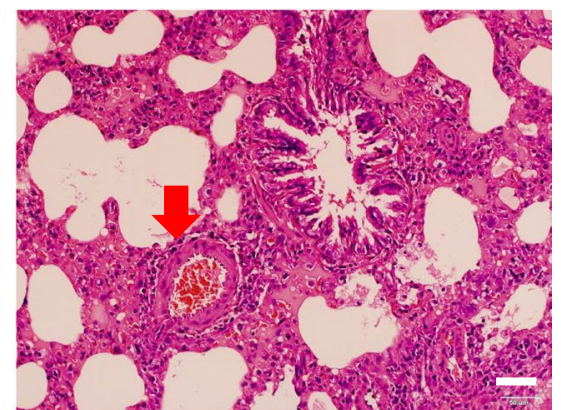

MCT+Fla

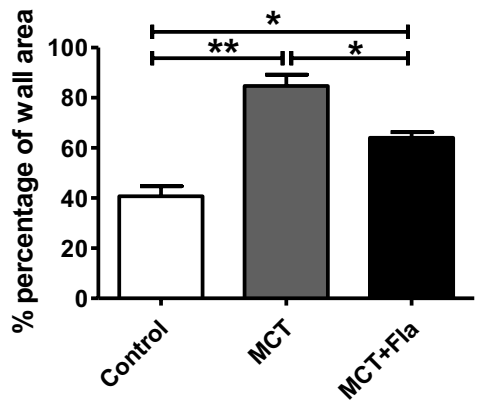

a-SMA

PCNA
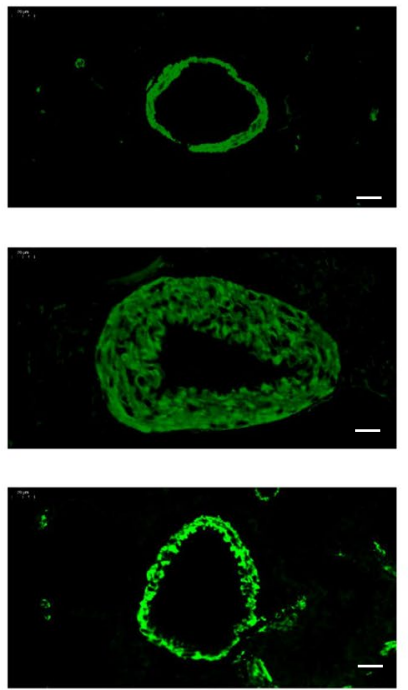
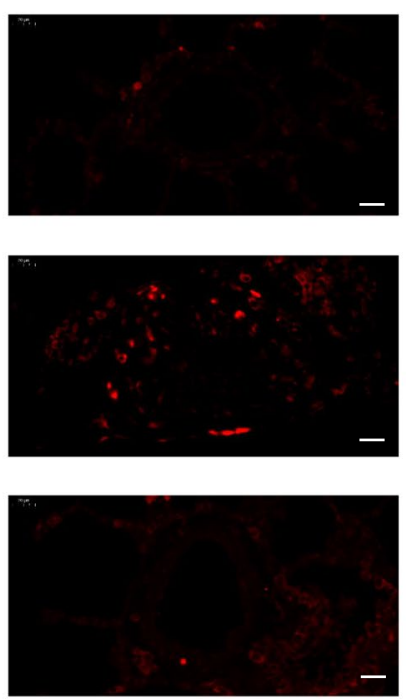

Merge
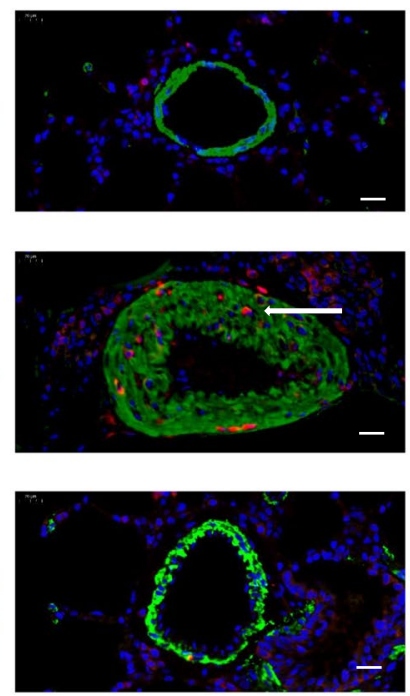

Fig. 3 Flavopiridol attenuated the vascular remodeling of MCTinduced pulmonary hypertension in rats. (A) Representative photograph of lung sections from the control, MCT and MCT plus flavopiridol groups. Red arrows indicated the small pulmonary arteries. Scale bar, $50 \mu \mathrm{m}$. (B) Summarized data of wall thickness and wall area of small pulmonary arteries from the control, MCT and MCT plus flavopiridol groups. (C) Confocal images of $\alpha$-SMA and PCNA positive cells in small pulmonary arteries from the control, MCT and MCT plus flavopiridol groups. White arrow indicated PCNA positive smooth muscle cells. Scale bar, $20 \mu \mathrm{m}$. MCT, monocrotaline; Fla, flavopiridol: Statistical analysis was performed with one-way ANOVA followed by Tukey-Kramer Multiple Comparison. $* P<0.05$, $* * P<0.01$. All values are expressed as the mean \pm SEM. $\mathrm{n}=5$ in each group

vascular remodeling [2, 9]. Hypoxia is an important stimulus for HPASMC proliferation and apoptotic resistance. Therefore, the effects of flavopiridol on the proliferation and apoptosis of hypoxia-treated and control HPASMCs were investigated. As shown in Fig. 4A, the viability of HPASMCs in the hypoxia group $\left(3 \% \mathrm{O}_{2}, 131.5 \pm 2.9 \%\right)$ 
was significantly higher than that of HPASMCs in the control group $\left(21 \% \mathrm{O}_{2}, 100.2 \pm 1.6 \%\right)$. Furthermore, flavopiridol strongly inhibited HPASMC proliferation in a concentration-dependent manner in the hypoxia group, especially when flavopiridol was used at $0.5 \mu \mathrm{M}$, which caused a 50\% decrease in cell viability, whereas flavopiridol minimally influenced HPASMC cell growth in the control group. Thus, flavopiridol treatment reversed the hypoxia-induced overproliferation of HPASMCs.

Additionally, in agreement with the CCK-8 assay results, the number of apoptotic HPASMCs was remarkably decreased under hypoxic conditions $(7.0 \pm 0.4 \%)$ compared to that observed in the normoxic control $(9.4 \pm 0.5 \%)$, while flavopiridol $(0.5 \mu \mathrm{M})$ significantly promoted the

A

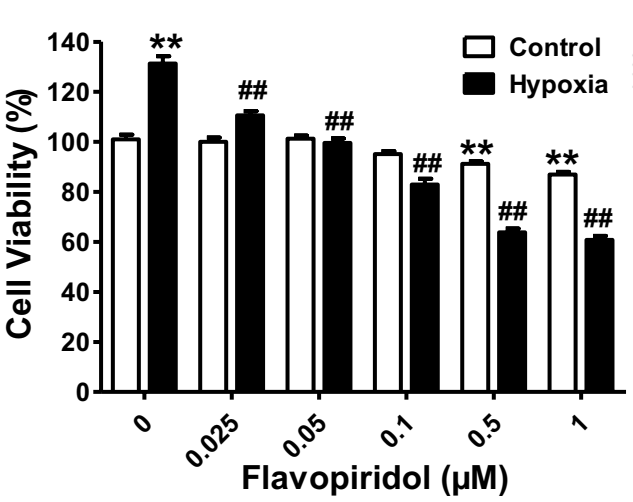

C
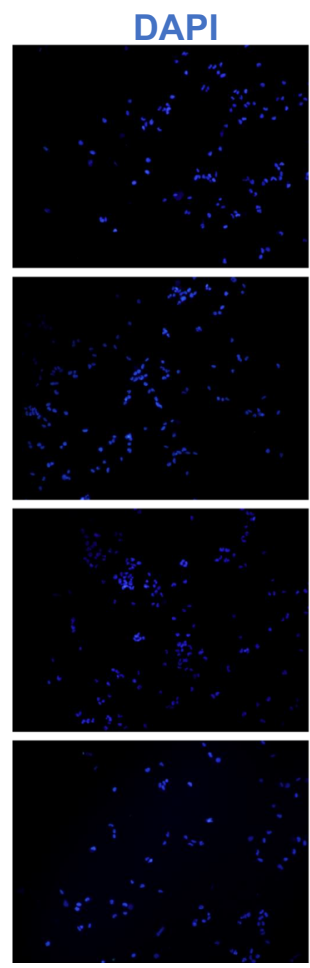

EdU
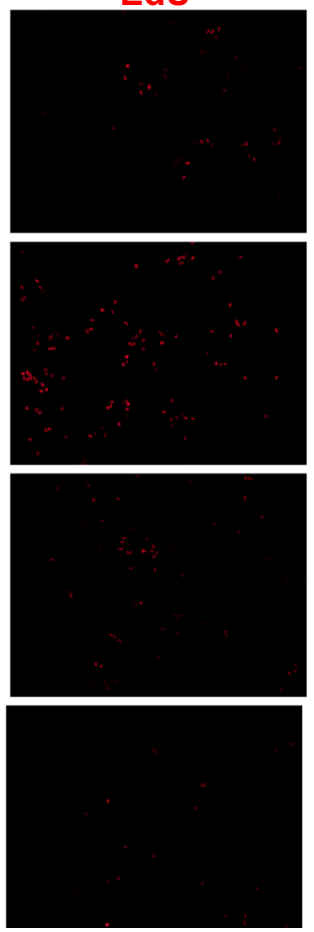

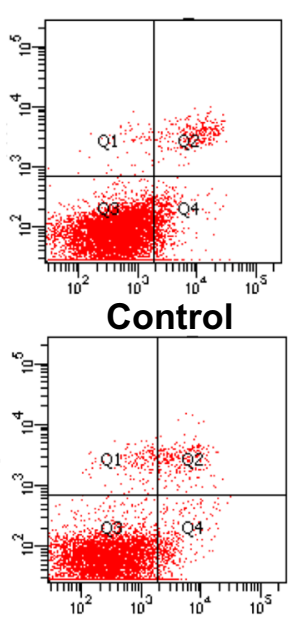

Fla

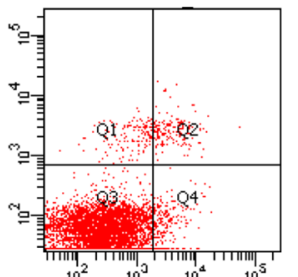

Hypoxia

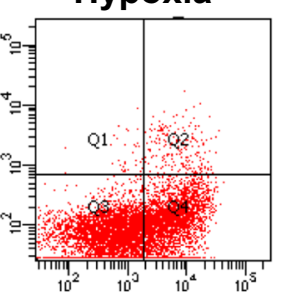

Hypoxia+Fla

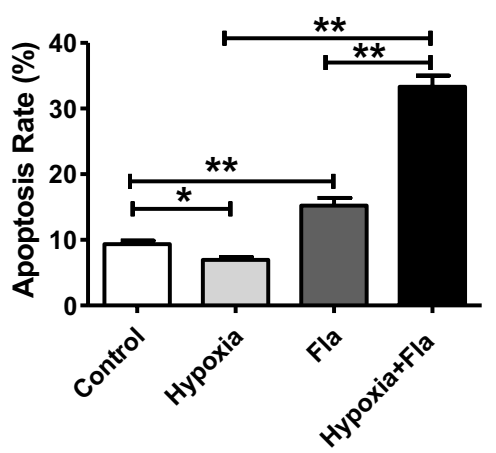

DAPI/EdU

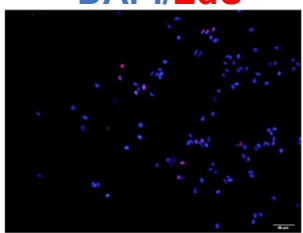

Control

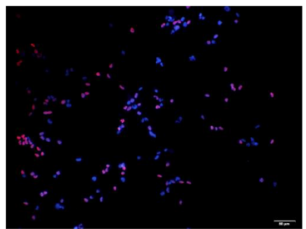

Hypoxia

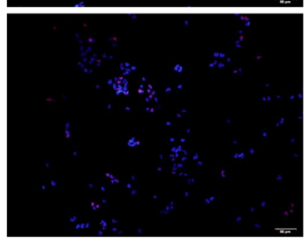

Fla
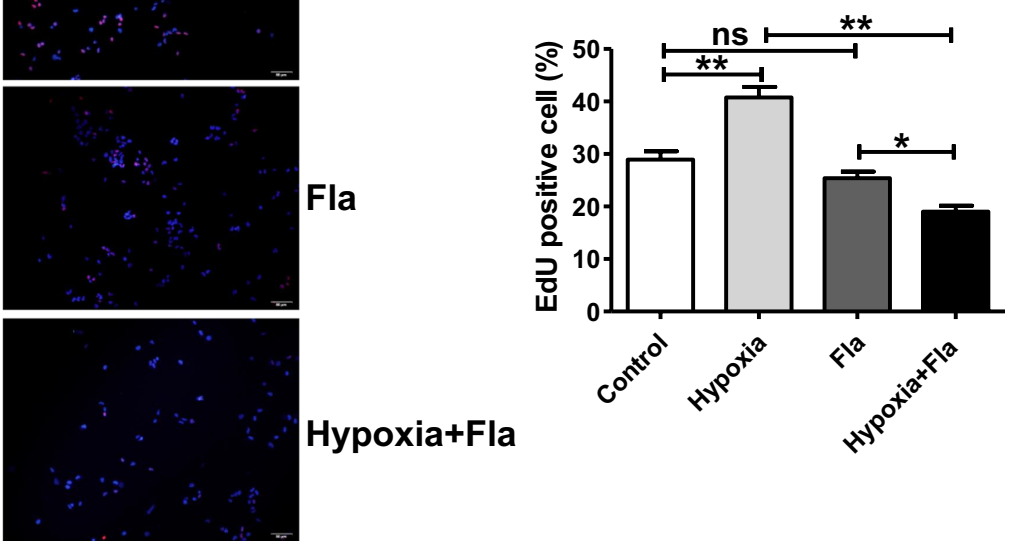

Hypoxia+Fla

Fig. 4 Flavopiridol inhibited the overproliferation and promoted the apoptosis of HPASMCs following subjected to hypoxia in vitro. (A) Effect of flavopiridol on the cell viability of human pulmonary artery smooth muscle cells (HPASMCs) in the control and hypoxia groups $(\mathrm{n}=10) . *$ vs control, \# vs Hypoxia. (B) Effects of hypoxia and flavopiridol on the apoptosis rate of HPASMCs $(n=6)$. (C) Representa- tive images (left panels) and the summarized data (right panels) of EdU positive cells in the control, hypoxia, flavopiridol and hypoxia plus flavopiridol groups $(n=6)$. Fla, flavopiridol: Statistical analysis was performed with two way ANOVA or one-way ANOVA followed by Tukey-Kramer Multiple Comparison. $* P<0.05$, $* * P<0.01$. All values are expressed as the mean \pm SEM 
apoptosis of hypoxia-treated HPASMCs (from $7.0 \pm 0.4 \%$ to $33.3 \pm 1.7 \%, \sim$ fivefold) but only minimally increased apoptosis of untreated HPASMCs (from $9.4 \pm 0.5 \%$ to $15.2 \pm 1.2 \%, \sim 1.6$-fold, Fig. 4B). Furthermore, hypoxia significantly increased the percentage of EdU-positive cells $(40.8 \pm 2.0 \%)$ compared to that observed in the normoxic control group $(28.9 \pm 2.0 \%)$, and flavopiridol dramatically reduced hypoxia-induced HPASMC overproliferation (from $40.8 \pm 2.0 \%$ to $19.0 \pm 1.1 \%$, Fig. 4 C) .

\section{Flavopiridol Inhibits CDK9-mediated Transcription Elongation and Suppresses the Expression of Downstream Prosurvival and Antiapoptotic Proteins in Pulmonary Arterial Tissues in PH Rats}

As flavopiridol has been previously reported to be a potent CDK9 inhibitor [23], we further examined whether flavopiridol inhibits CDK9 expression or kinase activity. Compared to that observed in the control group, CDK9 expression was significantly upregulated in the MCT group, and flavopiridol had no effect on MCT-induced CDK9 expression (Fig. 5). Subsequently, we examined the effect of flavopiridol on CDK9 kinase activity by measuring the cellular levels of RNA polymerase II phosphoforms at Ser-2, which is the specific site for RNA polymerase II phosphorylation by CDK9. Figures 5A, B show that significantly higher phosphorylation of RNA polymerase II at Ser-2 occurred in the MCT group $(0.93 \pm 0.04, P<0.05)$ than in the control group $(0.39 \pm 0.03)$. Interestingly, flavopiridol significantly reduced the phosphorylation of RNA polymerase II at Ser-2 in isolated pulmonary arterial tissues (from $0.93 \pm 0.04$ to $0.56 \pm 0.04$ ), but it had no effect on the total protein levels of RNA polymerase II in isolated pulmonary arterial tissues.

CDK9-mediated transcription of several prosurvival and antiapoptotic proteins (e.g., c-Myc, Mcl-1 and survivin) plays an important role in the proliferation and apoptosis resistance of cancer cells $[19,20]$, and the aforementioned prosurvival and antiapoptotic proteins are also involved in the pathology of $\mathrm{PH}[21,22]$. Thus, the effects of flavopiridol on the expression of c-Myc, Mcl-1, and survivin were examined. As shown in Fig. 5C-E, the mRNA and protein expression levels of c-Myc, Mcl-1, and survivin in isolated pulmonary arterial tissues of MCT-treated rats were significantly upregulated compared to those of the control group, and these downstream prosurvival and antiapoptotic proteins were decreased by flavopiridol treatment.

\section{CDK9-related Negative Regulators are Downregulated in PH}

Emerging evidence suggests that some CDK9-related negative regulators (e.g., HEXIM 1/2, LARP7, and MePCE) are also involved in CDK9-related diseases, e.g., cancers [28, 30]. Next, we examined whether these negative regulators are also involved in PH. Compared to the control group, decreased LARP7, HEXIM 1, and MePCE mRNA expression $(\sim 0.4$, $0.7,0.5$-fold change) was detected in pulmonary arterial tissues isolated from MCT-exposed rats, while no significant difference was observed in HEXIM 2 mRNA expression between the control and MCT-treated rats (Fig. 6).

\section{Discussion}

In the present study, we first revealed that CDK9 was upregulated in isolated pulmonary arterial tissues from MCTinduced PH rats in vivo and in hypoxic cultured HPASMCs in vitro. This upregulation of CDK9 was associated with increased CDK9-mediated phosphorylation of the CTD of RNA pol II at Ser-2. Second, several downstream prosurvival and antiapoptotic proteins (c-Myc, Mcl-1, and survivin) were also upregulated at both the mRNA and protein levels. These molecular changes in pulmonary arterial tissues were coincident with pathogenic enhancement of pulmonary vasculature remodeling and elevated pulmonary arterial pressure. Furthermore, flavopiridol significantly alleviated pulmonary artery remodeling and reversed the progression of PH through the inhibition of CDK9-mediated transcription elongation. Taken together, these findings elucidated the potential role and underlying mechanism of CDK9 in the pathogenesis of pulmonary vasculature remodeling under $\mathrm{PH}$, and flavopiridol partially reversed pathogenic vasculature remodeling in $\mathrm{PH}$ rats by targeting CDK9.

Growing evidence indicates that $\mathrm{PH}$ shares several similar pathogenic characteristics with cancers [6,7], and one of the most important similarities being that both cancer cells and PH-associated vascular cells, especially PASMCs, exhibit a proproliferative and antiapoptotic phenotype [3,6]. In the present study, the level of a cell proliferation biomarker (PCNA) in pulmonary arteries from MCT-induced PH rats was increased, and a significant hypertrophic media layer harboring proliferative PASMCs was observed in pulmonary small arteries. This overproliferation phenotype of vascular cells, especially PASMCs, will lead to an increased thickness of the pulmonary artery media wall, consequently promoting $\mathrm{PH}$ and right ventricle failure. Moreover, HPASMC overproliferation and resistance to apoptosis were also induced under hypoxic (3\%) conditions, similar to that observed in cancer cells exposed to a hypoxic environment [32]. Interestingly, this abnormal overproliferative and antiapoptotic phenotype of PAMSCs was reversed by treatment with the antitumor agent, flavopiridol, in both the in vivo $\mathrm{PH}$ model and in vitro HPASMCs, suggesting that reversing these cancer-like phenotypes may be a promising therapeutic strategy to combat $\mathrm{PH}$. 


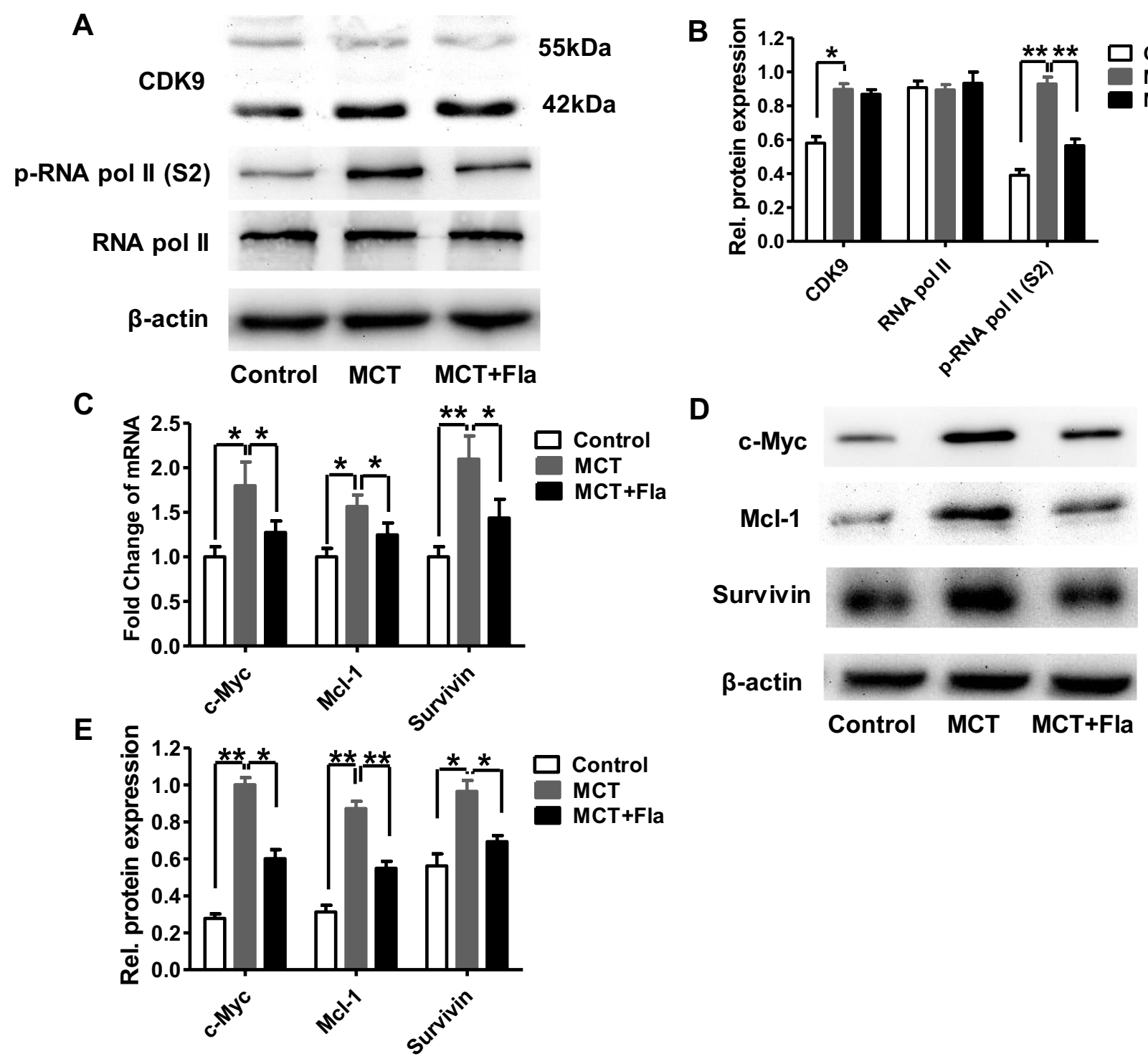

Fig. 5 Flavopiridol inhibited CDK9-mediated transcription elongation and suppressed the expression of downstream target proteins of pulmonary arterial tissues in MCT-induced pulmonary hypertension. (A-B) Representative images (A) and the summarized data (B) of expressions of CDK9, RNA polymerase II phosphoforms at Ser-2 and RNA polymerase II in the control, MCT and MCT plus flavopiridol

CDK9 is an emerging therapeutic target for cancer treatment, and upregulation of CDK9 has been identified in several cancers $[18,20]$, such as osteosarcoma, melanoma, and gastric cancer [16, 17, 33]. Consistent with these results, upregulation of CDK9 was also found in our study both in isolated pulmonary arterial tissues from MCT-induced PH rats in vivo and in hypoxic cultured HPASMCs in vitro. Another research group has also reported that CDK9 mRNA expression is increased in both mouse and rat experimental PH models [34], which further supports our hypothesis that CDK9 is also an important therapeutic target for PH. groups. (C-E) The mRNA (C) and protein (D, E) levels of expression of c-Myc, Mcl-1, survivin in the control, MCT and MCT plus flavopiridol groups. Statistical analysis was performed with oneway ANOVA followed by Tukey-Kramer Multiple Comparison. $* P<0.05, * * P<0.01$. All values are expressed as the mean \pm SEM. $\mathrm{n}=5$ in each group

Furthermore, enhanced CDK9-mediated transcription elongation increases the expression of prosurvival and antiapoptotic proteins, such as c-Myc, Mcl-1, and survivin, thereby contributing to the proproliferative and antiapoptotic phenotype of cancer cells $[12,18,20]$. CDK9 inhibitors, such as flavopiridol, SNS-032, and roscovitine, have been demonstrated to be efficient in cancer treatment through downregulation of these prosuvival and antiapoptotic proteins $[16,26$, 35]. Similarly, in our study, CDK9-mediated transcription elongation was also enhanced in pulmonary arterial tissues from MCT-induced PH rats and hypoxia-treated HPASMCs, 
A

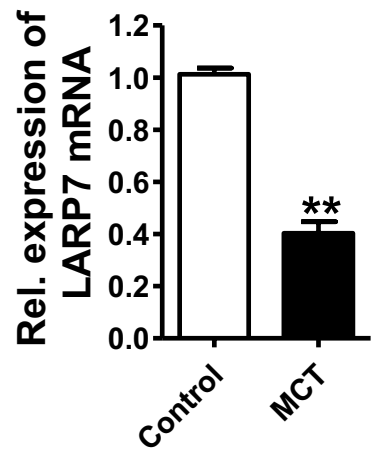

B

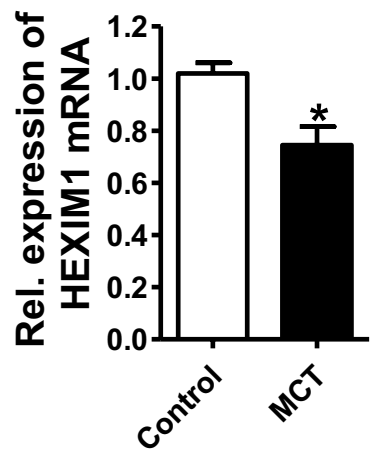

Fig. 6 CDK9-related negative regulators are downregulated in pulmonary hypertension. (A-D) The mRNA expression of LARP7, HEXIM1/2 and MePCE in pulmonary arterial tissues isolated

and the enhancement was associated with upregulation of the abovementioned prosurvival and antiapoptotic proteins, indicating that inhibition of CDK9-mediated transcription elongation and decreased expression of these downstream target proteins may also be efficient in the treatment of $\mathrm{PH}$.

Flavopiridol is a broadly specific CDK inhibitor with a distinct preference for CDK9. The $K_{\mathrm{i}}$ values of flavopiridol for CDK9/CycT (3 nM) have been previously shown to be approximately tenfold lower than those for other CDKs (40-70 nM) [36]. CDK9 inhibition by flavopiridol can remarkably attenuate tumor growth in vitro and in vivo [26, 27]. As previously observed in cancer cells [18], CDK9 upregulation was also detected in both pulmonary arterial tissues from MCT-induced PH rats and hypoxia-treated HPASMCs in the present study. Additionally, CDK9 inhibition by flavopiridol attenuated the overproliferation and promoted the apoptosis of PASMCs, thereby alleviating pulmonary vasculature remodeling and reversing the progression of PH in rats similar to its antitumor effects $[18,20]$. Taken together, these results showed that CDK9 upregulation also contributes to the overproliferative and antiapoptotic phenotypes of PH PASMCs similar to that observed in cancer cells.

As a catalytic subunit of P-TEFb, CDK9 activation promotes transcription elongation by phosphorylating RNA polymerase II CTD. In the present study, consistent with its potent inhibition of CDK9 kinase activity observed in cancer cells [26], flavopiridol also significantly reduced the phosphorylation of RNA polymerase II CTD at Ser-2 in isolated $\mathrm{PH}$ pulmonary arterial tissues, indicating a potential role of flavopiridol in reversing pulmonary vessel remodeling. Furthermore, the overexpression of several short-lived prosurvival and antiapoptotic proteins, such as c-Myc, Mcl-1, and survivin has been reported to contribute to the overproliferation and resistance to apoptosis phenotypes of cancer cells $[19,20]$, and these proteins are preferentially depleted

C

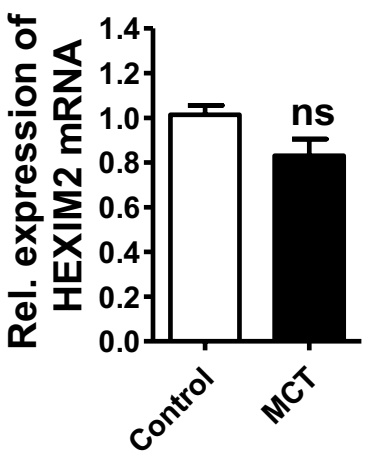

D

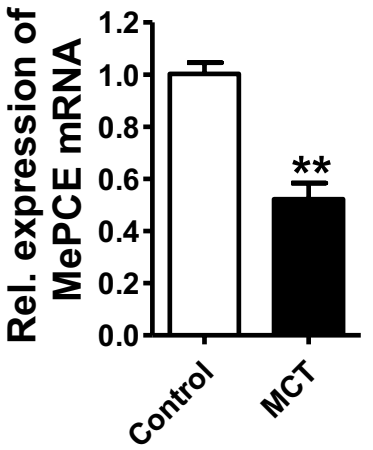

from the control and MCT-treated rats $(n=5$ in each group). Statistical analysis was performed with the student's $t$-test. ${ }^{*} P<0.05$, $* * P<0.01$. All values are expressed as the mean \pm SEM

by the inhibition of CDK9-mediated transcription elongation [13]. In agreement with the results of other studies [21, 22], both the mRNA and protein levels of c-Myc, Mcl-1, and survivin were also significantly increased in our isolated $\mathrm{PH}$ pulmonary arterial tissues. As described in previous studies, downregulation of these prosurvival and antiapoptotic proteins (e.g., survivin) decreases proliferation, induces apoptosis of PASMCs in vitro, and attenuates pulmonary artery hypertrophy, decreases pulmonary vascular resistance, and reverses the progression of $\mathrm{PH}$ in vivo [37]. Consistent with these results, in our study, inhibition of CDK9 by flavopiridol also significantly decreased the expression of prosurvival and antiapoptotic proteins as well as induced apoptosis and decreased the proliferation of PASMCs. Therefore, our results suggested that the antiproliferative and proapoptotic effects of flavopiridol on pulmonary arteries and PASMCs are mediated by the inhibition of CDK9-mediated transcription elongation and the expression of the abovementioned downstream target proteins.

In addition to changes in CDK9 expression or activity, CDK9/P-TEFb-related regulators may also be involved in CDK9-related diseases (e.g., cancers) [28, 30, 38]. As previously reported, LARP7, HEXIM1 or HEXIM2 and MePCE, bind to 7SK small nuclear RNA (snRNA) to form the 7SK small nuclear ribonucleoprotein (7SK snRNP) complex, which plays a role in inhibiting CDK9/P-TEFb activity [29, 30]. LARP7 has been previously reported to suppress CDK9/P-TEFb activity, and LARP7 knockdown or inhibition increases CDK9 activity [30]. HEXIM1/2 inhibits CDK9 kinase activity in a 7SK snRNA-dependent manner [29]. MePCE has been reported to stabilize 7SK snRNA to facilitate the inhibition of CDK9/P-TEFb activity [39]. In agreement with these findings, the present study demonstrated that the 7SK snRNP complex components [LARP7, HEXIM1 (not HEXIM2), and MePCE] were significantly decreased in isolated $\mathrm{PH}$ pulmonary arteries, suggesting 
that these CDK9-related negative regulators may also be involved in the pathology of $\mathrm{PH}$. Additionally, previous studies have reported that overexpression of these CDK9-related negative regulators (e.g., LARP7) decreases CDK9/P-TEFb kinase activity to reverse the progression of CDK9-related diseases [30,38]. Thus, the underlying mechanisms of these CDK9-related negative regulators in $\mathrm{PH}$ require further investigation.

Similar to other anticancer agents, however, flavopiridol $(0.5 \mu \mathrm{M})$ was still cytotoxic toward the control HPASMCs, demonstrating that some therapeutic strategies are needed to reduce the dose of flavopiridol to treat $\mathrm{PH}$. In the present study, three assayed CDK9-related negative regulators (LARP7, HEXIM1, and MePCE) were downregulated in isolated PH pulmonary arterial tissues. Future studies will investigate whether the overexpression of these proteins combined with CDK9 inhibition (flavopiridol) exert synergistic inhibitory effects toward CDK9-mediated transcription elongation to yield a more pronounced suppression of the development of $\mathrm{PH}$ and decrease side effects.

There were several limitations of the present study. First, due to the technical simplicity and reproducibility advantages, an MCT-induced PH model was used in the present study, but the differences between MCT models and human PH should be taken into consideration. MCT not only induces PH but also affects both the right and left ventricles as well as other organs (liver and kidney injuries), which may affect the progression of $\mathrm{PH}$ [40]. In subsequent studies, analyses of pulmonary artery samples from $\mathrm{PH}$ patients may be more convincing to evaluate the associated role of CDK9. Second, flavopiridol is a pan-CDK9 inhibitor and may alter transcription via other mechanisms in addition to CDK9 inhibition or may inhibit other CDKs but with lower efficacy [36]. Thus, it would be more convincing if a more specific CDK9 inhibitor (e.g., BAY-1143572) was used in subsequent studies [41]. Third, P-TEFb comprises CDK9 and cycin $\mathrm{T}$ ( $\mathrm{T} 1, \mathrm{~T} 2 \mathrm{a}$, or $\mathrm{T} 2 \mathrm{~b})$, and cyclin $\mathrm{T} 1$ is the primary CDK9 partner cyclin (approximately 80\%) [39]. In addition, cyclin $\mathrm{T} 1$ has also been reported to be overexpressed in cancer tissues compared to normal tissues, enhancing transcription elongation, and promoting tumor malignances [42]. However, whether cyclin $\mathrm{T} 1$ is upregulated and synergizes with CDK9 upregulation to facilitate the development of $\mathrm{PH}$ requires further investigation.

In summary, CDK9 upregulation and the subsequent enhanced activation of transcription elongation, which leads to increased downstream prosurvival and antiapoptotic protein expression, may be associated with the mechanisms involved in pulmonary artery remodeling and facilitate the progression of $\mathrm{PH}$. Flavopiridol significantly attenuates pulmonary artery remodeling and reverses the progression of $\mathrm{PH}$ by inhibiting CDK9-meditated transcription elongation. These findings may provide novel insights into the pathological mechanism of $\mathrm{PH}$, and CDK9 inhibition, such as flavopiridol treatment, should be considered a potential novel therapeutic strategy for $\mathrm{PH}$.

Authors' Contributions WKM, QJ conception and design of research study; QJ, ZQH and NNS performed experiments; QJ, ZQH analyzed the data and interpreted results of experiments; WKM, QJ wrote the manuscript. All authors read and approved the final manuscript.

Funding This work was supported by grant 81470251 (to Weike Mao) from the National Natural Science Foundation of China (Beijing, China).

Data Availability The data that support the finding of this study are available from the corresponding author upon reasonable request.

\section{Declarations}

Ethics Approval All experiments involving animals were performed with the approval of the Animals Care and Use Committee of Huazhong University of Science and Technology (Wuhan, Hubei, China).

Conflict of Interest The authors declare that they have no conflicts of interest.

Open Access This article is licensed under a Creative Commons Attribution 4.0 International License, which permits use, sharing, adaptation, distribution and reproduction in any medium or format, as long as you give appropriate credit to the original author(s) and the source, provide a link to the Creative Commons licence, and indicate if changes were made. The images or other third party material in this article are included in the article's Creative Commons licence, unless indicated otherwise in a credit line to the material. If material is not included in the article's Creative Commons licence and your intended use is not permitted by statutory regulation or exceeds the permitted use, you will need to obtain permission directly from the copyright holder. To view a copy of this licence, visit http://creativecommons.org/licenses/by/4.0/.

\section{References}

1. Hoeper MM, Humbert M, Souza R, Idrees M, Kawut SM, SliwaHahnle K, et al. A global view of pulmonary hypertension. Lancet Respir Med. 2016;4:306-22.

2. Thenappan T, Ormiston ML, Ryan JJ, Archer SL. Pulmonary arterial hypertension: pathogenesis and clinical management. BMJ. 2018;360:j5492.

3. Luo Y, Teng X, Zhang L, Chen J, Liu Z, Chen X, et al. CD146HIF- $1 \alpha$ hypoxic reprogramming drives vascular remodeling and pulmonary arterial hypertension. Nat Commun. 2019;10:3551.

4. Dai Z, Zhu MM, Peng Y, Machireddy N, Evans CE, Machado R, et al. Therapeutic targeting of vascular remodeling and right heart failure in pulmonary arterial hypertension with a HIF- $2 \alpha$ inhibitor. Am J Respir Crit Care Med. 2018;198:1423-34.

5. Archer SL. Pyruvate kinase and warburg metabolism in pulmonary arterial hypertension: uncoupled glycolysis and the cancerlike phenotype of pulmonary arterial hypertension. Circulation. 2017;136:2486-90. 
6. Boucherat O, Vitry G, Trinh I, Paulin R, Provencher S, Bonnet S. The cancer theory of pulmonary arterial hypertension. Pulm Circ. 2017;7:285-99.

7. Pullamsetti SS, Savai R, Seeger W, Goncharova EA. Translational advances in the field of pulmonary hypertension. From cancer biology to new pulmonary arterial hypertension therapeutics. Targeting cell growth and proliferation signaling hubs. Am J Respir Crit Care Med. 2017;195:425-37.

8. Yeligar SM, Kang BY, Bijli KM, Kleinhenz JM, Murphy TC, Torres $\mathrm{G}$, et al. PPAR $\gamma$ regulates mitochondrial structure and function and human pulmonary artery smooth muscle cell proliferation. Am J Respir Cell Mol Biol. 2018;58:648-57.

9. You B, Liu Y, Chen J, Huang X, Peng H, Liu Z, et al. Vascular peroxidase 1 mediates hypoxia-induced pulmonary artery smooth muscle cell proliferation, apoptosis resistance and migration. Cardiovasc Res. 2018;114:188-99.

10. Lim S, Kaldis P. Cdks, cyclins and CKIs: roles beyond cell cycle regulation. Development. 2013;140:3079-93.

11. Paparidis NF, Durvale MC, Canduri F. The emerging picture of CDK9/P-TEFb: more than 20 years of advances since PITALRE. Mol Biosyst. 2017;13:246-76.

12. Eberhardy SR, Farnham PJ. c-Myc mediates activation of the cad promoter via a post-RNA polymerase II recruitment mechanism. J Biol Chem. 2001;276:48562-71.

13 Lemke J, von Karstedt S, Abd El Hay M, Conti A, Arce F, Montinaro A, et al. Selective CDK9 inhibition overcomes TRAIL resistance by concomitant suppression of cFlip and Mcl-1. Cell Death Differ. 2014;21:491-502.

14. Zhang H, Pandey S, Travers M, Sun H, Morton G, Madzo J, et al. Targeting CDK9 reactivates epigenetically silenced genes in cancer. Cell. 2018;175:1244-58.e26.

15. Sano M, Abdellatif M, Oh H, Xie M, Bagella L, Giordano A, et al. Activation and function of cyclin T-Cdk9 (positive transcription elongation factor-b) in cardiac muscle-cell hypertrophy. Nat Med. 2002;8:1310-7.

16. Zhang J, Liu S, Ye Q, Pan J. Transcriptional inhibition by CDK7/9 inhibitor SNS-032 abrogates oncogene addiction and reduces liver metastasis in uveal melanoma. Mol Cancer. 2019;18:140.

17. Lu Y, Tang L, Zhang Q, Zhang Z, Wei W. MicroRNA-613 inhibits the progression of gastric cancer by targeting CDK9. Artif Cells Nanomed Biotechnol. 2018;46:980-4.

18. Franco LC, Morales F, Boffo S, Giordano A. CDK9: a key player in cancer and other diseases. J Cell Biochem. 2018;119:1273-84.

19. Dang CV. MYC on the path to cancer. Cell. 2012;149:22-35.

20. Huang $\mathrm{CH}$, Lujambio A, Zuber J, Tschaharganeh DF, Doran MG, Evans MJ, et al. CDK9-mediated transcription elongation is required for MYC addiction in hepatocellular carcinoma. Genes Dev. 2014;28:1800-14

21. Steiner MK, Syrkina OL, Kolliputi N, Mark EJ, Hales CA, Waxman AB. Interleukin- 6 overexpression induces pulmonary hypertension. Circ Res. 2009; 104:236-44.

22. Miyagawa K, Shi M, Chen PI, Hennigs JK, Zhao Z, Wang M, et al. Smooth muscle contact drives endothelial regeneration by BMPR2-Notch1-mediated metabolic and epigenetic changes. Circ Res. 2019;124:211-24.

23. Wang LM, Ren DM. Flavopiridol, the first cyclin-dependent kinase inhibitor: recent advances in combination chemotherapy. Mini Rev Med Chem. 2010;10:1058-70.

24. Ji J, Mould DR, Blum KA, Ruppert AS, Poi M, Zhao Y, et al. A pharmacokinetic/pharmacodynamic model of tumor lysis syndrome in chronic lymphocytic leukemia patients treated with flavopiridol. Clin Cancer Res. 2013;19:1269-80.

25. Ruef J, Meshel AS, Hu Z, Horaist C, Ballinger CA, Thompson LJ, et al. Flavopiridol inhibits smooth muscle cell proliferation in vitro and neointimal formation In vivo after carotid injury in the rat. Circulation. 1999;100:659-65.
26. Gojo I, Zhang B, Fenton RG. The cyclin-dependent kinase inhibitor flavopiridol induces apoptosis in multiple myeloma cells through transcriptional repression and down-regulation of Mcl1. Clin Cancer Res. 2002;8:3527-38.

27. Zhou L, Zhang Y, Sampath D, Leverson J, Dai Y, Kmieciak M, et al. Flavopiridol enhances ABT-199 sensitivity in unfavourablerisk multiple myeloma cells in vitro and in vivo. Br J Cancer. 2018;118:388-97.

28. Ketchart W, Smith KM, Krupka T, Wittmann BM, Hu Y, Rayman PA, et al. Inhibition of metastasis by HEXIM1 through effects on cell invasion and angiogenesis. Oncogene. 2013;32:3829-39.

29. Michels AA, Fraldi A, Li Q, Adamson TE, Bonnet F, Nguyen VT, et al. Binding of the 7SK snRNA turns the HEXIM1 protein into a P-TEFb (CDK9/cyclin T) inhibitor. EMBO J. 2004;23:2608-19.

30. Ji X, Lu H, Zhou Q, Luo K. LARP7 suppresses P-TEFb activity to inhibit breast cancer progression and metastasis. Elife. 2014;3:e02907.

31. Zhang M, Xin W, Ma C, Zhang H, Mao M, Liu Y, et al. Exosomal 15-LO2 mediates hypoxia-induced pulmonary artery hypertension in vivo and in vitro. Cell Death Dis. 2018;9:1022.

32. Lee SH, Hyeon DY, Yoon SH, Jeong JH, Han SM, Jang JW, et al. RUNX3 methylation drives hypoxia-induced cell proliferation and antiapoptosis in early tumorigenesis. Cell Death Differ. 2020;28:1254-69.

33. Ma H, Seebacher NA, Hornicek FJ, Duan Z. Cyclin-dependent kinase 9 (CDK9) is a novel prognostic marker and therapeutic target in osteosarcoma. EBioMedicine. 2019;39:182-93.

34. Weiss A, Neubauer MC, Yerabolu D, Kojonazarov B, Schlueter BC, Neubert L, et al. Targeting cyclin-dependent kinases for the treatment of pulmonary arterial hypertension. Nat Commun. 2019;10:2204.

35. Kim EH, Kim SU, Shin DY, Choi KS. Roscovitine sensitizes glioma cells to TRAIL-mediated apoptosis by downregulation of survivin and XIAP. Oncogene. 2004;23:446-56.

36. Chao SH, Fujinaga K, Marion JE, Taube R, Sausville EA, Senderowicz AM, et al. Flavopiridol inhibits P-TEFb and blocks HIV-1 replication. J Biol Chem. 2000;275:28345-8.

37. McMurtry MS, Archer SL, Altieri DC, Bonnet S, Haromy A, Harry G, et al. Gene therapy targeting survivin selectively induces pulmonary vascular apoptosis and reverses pulmonary arterial hypertension. J Clin Invest. 2005;115:1479-91.

38. Tan JL, Fogley RD, Flynn RA, Ablain J, Yang S, Saint-André $\mathrm{V}$, et al. Stress from nucleotide depletion activates the transcriptional regulator HEXIM1 to suppress melanoma. Mol Cell. 2016;62:34-46.

39. Bacon CW, D’Orso I. CDK9: a signaling hub for transcriptional control. Transcription. 2019;10:57-75.

40. Gomez-Arroyo JG, Farkas L, Alhussaini AA, Farkas D, Kraskauskas D, Voelkel NF, et al. The monocrotaline model of pulmonary hypertension in perspective. Am J Physiol Lung Cell Mol Physiol. 2012;302:L363-9.

41. Lücking U, Scholz A, Lienau P, Siemeister G, Kosemund D, Bohlmann R, et al. Identification of Atuveciclib (BAY 1143572), the first highly selective, clinical PTEFb/CDK9 inhibitor for the treatment of cancer. ChemMedChem. 2017;12:1776-93.

42. Moiola C, De Luca P, Gardner K, Vazquez E, De Siervi A. Cyclin $\mathrm{T} 1$ overexpression induces malignant transformation and tumor growth. Cell Cycle. 2010;9:3119-26.

Publisher's Note Springer Nature remains neutral with regard to jurisdictional claims in published maps and institutional affiliations. 